\title{
Nutrition Education in Australian Midwifery Programmes: A Mixed-Methods Study
}

\author{
Jamila Arrish, ${ }^{1}$ Heather Yeatman, ${ }^{1}$ and Moira Williamson ${ }^{2,3}$ \\ ${ }^{1}$ School of Health and Society, Faculty of Social Sciences, University of Wollongong, Northfields Avenue, Wollongong, \\ NSW 2522, Australia \\ ${ }^{2}$ School of Nursing, Faculty of Science, Medicine \& Health, University of Wollongong, Northfields Avenue, Wollongong, \\ NSW 2522, Australia \\ ${ }^{3}$ School of Nursing and Midwifery, Higher Education Division, Central Queensland University, 90 Goodchap Street, \\ Noosaville, QLD 4566, Australia
}

Correspondence should be addressed to Jamila Arrish; jma604@uowmail.edu.au

Received 13 July 2016; Revised 15 October 2016; Accepted 15 November 2016

Academic Editor: Dragan Ilic

Copyright (C) 2016 Jamila Arrish et al. This is an open access article distributed under the Creative Commons Attribution License, which permits unrestricted use, distribution, and reproduction in any medium, provided the original work is properly cited.

\begin{abstract}
Little research has explored how nutrition content in midwifery education prepares midwives to provide prenatal nutrition advice. This study examined the nature and extent of nutrition education provided in Australian midwifery programmes. A mixed-methods approach was used, incorporating an online survey and telephone interviews. The survey analysis included 23 course coordinators representing 24 of 50 accredited midwifery programmes in 2012. Overall, the coordinators considered nutrition in midwifery curricula and the midwife's role as important. All programmes included nutrition content; however, eleven had only 5 to $<10$ hours allocated to nutrition, while two had a designated unit. Various topics were covered. Dietitians/other nutrition experts were rarely involved in teaching or reviewing the nutrition content. Interviews with seven coordinators revealed that nutrition education tended to be problem-oriented and at times based on various assumptions. Nutrition content was not informed by professional or theoretical models. The development of nutrition assessment skills or practical training for midwifery students in providing nutrition advice was lacking. As nutrition is essential for maternal and foetal health, nutrition education in midwifery programmes needs to be reviewed and minimum requirements should be included to improve midwives' effectiveness in this area. This may require collaboration between nutrition experts and midwifery bodies.
\end{abstract}

\section{Introduction}

The importance of nutrition during pregnancy for mother and offspring is supported by a growing body of evidence [1, 2]. Pregnant women often display nutrition information seeking behaviour [3]. Information and advice about healthy eating during pregnancy/breast-feeding and about weight management are some of the topics specifically requested by pregnant women [4]. Health professionals rate the provision of nutrition advice during pregnancy as important/very important [5]. However, the proportion of those professionals providing advice across different nutrition topics is low (16-32\%) [5] and a majority of pregnant women do not receive appropriate nutrition advice from their health professionals [6].
Australian pregnant women have poor nutrition knowledge and behaviour despite being highly motivated and confident in their ability to adopt a healthy diet [7]. The midwife is considered a trusted source of information by pregnant women [8]. Australian midwives believe nutrition during pregnancy is important and they have a role in providing nutrition advice to pregnant women [9]. However, their nutrition knowledge has been found to be lacking and only half report receiving nutrition education within their midwifery education or during practice [9]. Educational gaps on particular aspects related to maternal nutrition, obesity, and weight management were indicated in international and Australian research [10-14]. Attempts by two international universities to integrate nutrition within their curricula were 
briefly reported $[15,16]$. There is a paucity of research about nutrition education provided in midwifery programmes.

In Australia, midwifery education is offered through both undergraduate and postgraduate programmes. Midwifery education is overseen by the Australian Nursing and Midwifery Council (ANMC). The name of the council has changed to the Australian Nursing and Midwifery Accreditation Council (ANMAC), reflecting its role as the independent accrediting authority which sets the standards of accreditation for midwifery programmes (with the latest version released in October 2014) [17, 18]. The Nursing and Midwifery Board of Australia (NMBA), the regulatory body of the nursing and midwifery professions in Australia, approves the accredited programmes [17].

Successfully completing a midwifery programme accredited under the ANMAC Midwife Accreditation Standards enables graduates to apply for registration as a midwife in Australia [17]. The ANMAC published the first National Competency Standards for the Midwife in 2006 following two years of research/development and validation, and they undergo regular review and revision $[17,19]$. These competency standards include the core competencies used by registration authorities, education providers, and employers to assess if a midwife is competent for registration and practice [17].

The previous Accreditation Standards [18] did not have any mention of nutrition [20]. The current ANMAC Midwife Accreditation Standards [17] have undergone minimal change in this regard. They emphasise that the curricula should be underpinned by "primary health care principles" which include "promotion of food supply and proper nutrition" [17]. However, they do not stipulate any specific nutrition education requirements to be included in the curricula. The National Competency Standards for the Midwife specify public health issues that need to be addressed by the midwife, such as "promotion of breast-feeding," "smoking cessation," "domestic violence," and "drugs or alcohol use" [19]. There is no mention of nutrition or the promotion of healthy eating. According to the International Confederation of Midwives (ICM) Essential Competencies for Basic Midwifery Practice [21] (revised 2013), midwives should have "the knowledge and/or understanding of nutritional requirements of the pregnant woman and foetus" and "the skill and/or ability to assess maternal nutrition and its relationship to foetal growth; give appropriate advice on nutritional requirements of pregnancy and how to achieve them" (pp. 8 \& 9). It would be expected that midwives require adequate education to provide such advice.

This study examined the nature and extent of nutrition education provided in Australian midwifery programmes.

\section{Methodology}

2.1. Study Design. The study used a mixed-methods approach and consisted of two components: an online survey and semi-structured interviews. A convergence parallel design was utilised for the overall study. In this design, quantitative and qualitative data are collected and analysed independently within the same time frame of the research process (ideally given the same priority) and the results of both data are merged in the overall interpretation [22]. The main purpose of this design is to obtain a comprehensive understanding of the topic under study and to validate or corroborate the results from one method with the results of the other [22].

\subsection{Stage 1: The Survey}

2.2.1. The Purpose. The purpose of the survey was to investigate the extent and nature of nutrition education provided in Australian midwifery undergraduate and postgraduate programmes and the views of midwifery coordinators on the midwife's role in nutrition education and the importance of nutrition in midwifery curricula.

2.2.2. Respondents and Survey Dissemination. The list (as at 1 May 2012) of all Australian accredited midwifery programmes leading to professional registration as approved by the NMBA was obtained from their website. The list included 50 programmes comprising 23 undergraduate and 27 postgraduate degrees from 29 universities, the name of the approved institution/provider, the qualification provided (type of the programme, e.g., undergraduate or postgraduate), the state or territory in which the programme was provided, and the period of accreditation.

Course coordinators were deemed the appropriate point of contact, as the ANMC accreditation standards [18] did not have specific requirements for nutrition education within curricula, and the coordinator would have an overview of their programme content. The contact details of course coordinators for the identified programmes were obtained through searching of institutional websites and telephone enquiry. The coordinators were contacted via email and invited to participate in the study and complete the online survey. The invitation email had brief information about the study, its aims, and the researchers' contact details. It also had a hyperlink to the online survey. Three reminders were sent to non-respondents at one month, three months, and four months from the issue of the invitation. Survey responses were collected from June to December 2012.

2.2.3. Survey Development and Structure. Only one survey investigating nutrition education of midwifery programmes was identified when the current study commenced [14] but it had a slightly different aim and was based on the United States of America's specific nutrition competencies. Therefore, it was deemed not relevant to Australia for the purpose of this study.

A short survey consisting of 10 items was developed. Coordinators were asked to indicate the degree/s they were coordinating, nominate the total number of hours allocated to nutrition in the curricula, nominate from a list of nutrition topics those covered in their curricula (formulated from prior literature and government websites) [20, 23-25], indicate the professional qualifications of content providers, report the frequency of content review, indicate the involvement of experts in the review process and the qualifications of reviewers, and express their own views on the midwife's role in nutrition education during pregnancy, including the significance of this role and the importance of nutrition 
education in midwifery curricula and for the clinical practice of midwives. Respondents were asked to rank their agreement with survey items using five-point scales (e.g., "very important," "moderately important," "important," "slightly important," and "not at all important"). Space was provided for respondents to supply any additional options or comments.

Two experts (in public health nutrition and midwifery) and a dietitian reviewed the survey for content, readability, and relevance. As a pilot, the survey was then sent to five researchers and two course coordinators, one of whom was a coordinator of a midwifery programme. Minor modifications were undertaken based on their feedback. SurveyMonkey Software (SurveyMonkey Inc., Palo Alto, California, USA, https://www.surveymonkey.com) was used to make the amended survey available online.

2.2.4. Data Analysis. The Statistical Package for the Social Sciences (SPSS) Software version 22 (Armonk, NY: IBM Corp.) was used for the analysis. Responses were reported by frequency and percentage. Fisher's exact test was used to examine the association between nutrition topics covered and programme type (i.e., undergraduate or postgraduate), and it was also used to examine the association between nutrition topics covered and seeking experts' advice in reviewing the programme's nutrition content. The association between hours allocated to nutrition and programme type was also examined. The answer of one coordinator who coordinated both undergraduate and postgraduate programmes at their institution was excluded in the comparison of nutrition topics between undergraduate and postgraduate midwifery programmes as their answer to that question related to both programmes and not one or the other. Statistical significance was set at alpha level of 0.05 .

Responses on hours allocated to nutrition were categorized into four categories ( $<5$ hours, 5 to $<10$ hours, 10 to $<15$ hours, and 15 hours or more). The four categories were combined into two categories $(<10$ hours or 10 hours and more) for the purpose of statistical analysis due to small numbers in some categories. Responses to open-ended survey questions were categorised and described.

\subsection{Stage 2: The Interviews}

2.3.1. The Purpose. The purpose of the interviews was to explore the coordinators' perspectives on how nutrition is incorporated within their programmes and deepen the understanding of the findings of the quantitative study.

2.3.2. Data Collection. Qualitative description was the approach chosen for this study [26]. Semi-structured telephone interviews were used to collect the data. In the email invitation to participate in the survey, a note about further contact at a later time for an interview and its purpose was included and the coordinators were asked to email the researcher if they were interested to participate in the interviews. Those who did were contacted at that time and interviewed. Further invitations to participate in the interviews were emailed to the other coordinators in January 2013 and a reminder to non-respondents was sent in February 2013.
The semi-structured interviews were conducted and audio-recorded via the telephone by the lead author (JA) between November 2012 and March 2013. They lasted between 11 and 26 minutes with an average time of 15 minutes. An interview guide was used as shown in the following

(1) Can you please outline how food and nutrition issues are presented within the midwifery curriculum at your institution?

(a) What importance, if any, is placed on teaching about nutrition during pregnancy compared to other topics in your programme?

(b) Who is responsible for the nutrition components in your programme? Can you please outline any particular qualifications in nutrition held by these academics/guests?

(2) Can you please outline the development and review activities linked with the nutrition curriculum within your programme?

(3) Please outline how nutrition curriculum within your programme is informed by particular pedagogical or professional theoretical models.

(4) Are there any particular aspects of the curriculum that assist to prepare your graduates to provide evidence-based nutrition information?

(a) Any national standards that you follow?

(b) Development of nutrition assessment skills?

(c) Practical training in nutrition?

(5) How well do you think graduate midwives from your programme are prepared to provide evidence-based nutrition information for pregnant women?

(a) Are there any particular barriers that may impede them in this role? What facilitates their practice in this role?

(6) Do you have any other points that you would like to raise?

The questions were reviewed by the co-authors, two experts (midwifery and public health), and a dietitian. One interview was conducted with a midwifery course coordinator as a pilot.

2.3.3. Data Analysis. The interviews were transcribed verbatim by a professional transcriber and checked for accuracy by JA. Data analysis was facilitated by using QSR International's NVivo 11 Software. The interviews were analysed thematically in a descriptive manner. The lead author read and reread the transcripts to become immersed in the data. All the authors coded one transcript independently and another one as a group and discussed the coding. The lead author then coded the rest of the transcripts and discussed the coding of all transcripts with one or both of the co-authors until consensus was reached. The lead author organised the descriptive themes, finalised the analysis, and confirmed the final results with the co-authors. 
TABLE 1: Overview of the respondents and included programmes.

\begin{tabular}{|c|c|c|c|}
\hline & $\begin{array}{l}n \text { of coordinators and } \\
\text { programmes included in the } \\
\text { study }\end{array}$ & $\begin{array}{l}n \text { of invited coordinators and } \\
\text { accredited programmes in } \\
2012\end{array}$ & $\%$ \\
\hline Respondents & 23 & 41 & 56.1 \\
\hline Programmes & 24 & 50 & 48.0 \\
\hline Undergraduate & 14 & 23 & 60.9 \\
\hline Bachelor of Midwifery & 11 & & \\
\hline Bachelor of Nursing/Bachelor of Midwifery & 3 & & \\
\hline Postgraduate & 10 & 27 & 37.0 \\
\hline
\end{tabular}

2.4. Ethical Considerations. Ethical approval was received from the University of Wollongong Health and Medical Human Research Ethics Committee (HE12/038). The coordinators indicated their consent in the survey by completing it and provided consent for the interviews either orally or in a written format.

\section{Results}

3.1. Stage 1. Forty-four identified coordinators from 50 programmes (some coordinators coordinated more than one programme) were sent the invitation; however, three coordinators were excluded based on failed delivery of invitation, discontinuation of the programme, and duplicate invitations for one programme. Therefore, the final number of potential respondents was 41 .

A total of 25 responses were received but one was excluded from the analysis due to insufficient data. For one programme (Bachelor of Nursing/Bachelor of Midwifery (double degree)) the survey was completed by two respondents (the overall coordinator of undergraduate degrees in that school and the course coordinator of the double degree). As the survey was intended to have only one response from each programme, only the response from the coordinator of the double degree was included in the analysis.

Table 1 shows the number of respondents and the details of programme type and frequency. The final response rate of the survey was $56.1 \%$ (23 of 41). One of the included survey respondents coordinated both undergraduate and postgraduate programmes at their institutions, while the remaining respondents each represented a single programme. Twentyfour accredited programmes were included, representing $48 \%$ of the programmes originally listed on the NMBA list. To preserve anonymity, the respondents were not asked to identify their university.

When asked if midwives had a professional role in educating pregnant women about nutrition, all except one of the course coordinators responded "yes" $(95.7 \%, n=22)$. Of these course coordinators, the majority $(63.6 \%, n=14)$ thought this role was "very significant," $22.7 \%(n=5)$ rated it as "moderately significant," and $13.6 \%(n=3)$ rated it as "significant."

The majority $(91.3 \%, 21$ of 23$)$ of the respondents considered nutrition in midwifery curriculum and nutrition education during pregnancy for midwives in clinical practice to be important on some level with the same proportions $(30.4 \%$ $(n=7)$ and $8.7 \%(n=2))$ rating them as "very important" and "slightly"/"not important," respectively. Slightly over a third $(34.8 \%, n=8)$ rated nutrition in midwifery curriculum as "moderately important," while $30.4 \%(n=7)$ chose the same rating for nutrition education during pregnancy for midwives in clinical practice. The proportions that rated nutrition in midwifery curriculum and nutrition education for practising midwives as "important" were $26.1 \%(n=6)$ and $30.4 \%$ $(n=7)$, respectively.

Sixteen coordinators representing 17 programmes provided a discrete number of hours allocated to general nutrition and/or nutrition during pregnancy, while five provided an approximate range. Two coordinators did not provide a value or estimation. The number of hours spent in total on nutrition education during their programmes ranged from 2 to 48 hours. Figure 1 illustrates the hours allocated to general nutrition and/or nutrition during pregnancy in midwifery curricula by programme type. Half of the programmes (11 of 22 ) had 5 to $<10$ hours of nutrition content ( 6 undergraduate and 5 postgraduate programmes). Three coordinators reported that $<5$ hours were allocated to nutrition in their programmes, and four reported 10 to $<15$ hours or 15 or more hours of nutrition content. Only undergraduate programmes had 15 hours or more of nutrition content $(n=4)$. Two programmes had designated nutrition units and these made up half of the programmes that had 15 hours or more (2 of 4).

Four respondents reported that, other than the stated hours, nutrition content was embedded within other subjects and one respondent indicated that a new subject on nutrition was planned to be included in the curriculum. Reading/class exercises and academic assessments that included a nutrition focus were mentioned by two coordinators. Two other coordinators highlighted that students were likely to be exposed to education on nutrition during clinical placement. No significant association was found between hours allocated to nutrition and programme type.

All of the respondents indicated that midwives were involved in providing the nutrition content of their programmes. Five respondents indicated that dietitians or nutritionists were also involved in providing nutrition content. Six respondents identified other health professionals (such as scientists, nurses, and lactation consultants) as involved in providing nutrition content.

Table 2 shows the nutrition topics covered in the participating midwifery programmes. Various topics of nutrition 
TABLE 2: Nutrition topics covered in participating midwifery programmes.

\begin{tabular}{|c|c|c|}
\hline Topics & Number $^{(a)}$ & $\%$ \\
\hline \multicolumn{3}{|l|}{ (1) Topics of nutrition during pregnancy } \\
\hline Alcohol and pregnancy & 23 & 100 \\
\hline Nutrition related issues such as managing nausea and vomiting & 23 & 100 \\
\hline Nutrition during pregnancy, for example, the role of folate, iodine, or calcium & 22 & 95.7 \\
\hline The healthy range of weight gain required for pregnant women & 22 & 95.7 \\
\hline Nutrition for breastfeeding & 21 & 91.3 \\
\hline Nutrition management of gestational diabetes & 20 & 87.0 \\
\hline Food safety and preparation during pregnancy (e.g., listeria) & 19 & 82.6 \\
\hline Managing weight during pregnancy & 16 & 69.6 \\
\hline Nutrition assessment (e.g., reviewing diet for nutrition requirements of pregnancy) & 15 & 65.2 \\
\hline Nutrition and teenage pregnancy & 11 & 47.8 \\
\hline Nutrition during pregnancy and different cultural groups & 10 & 43.5 \\
\hline \multicolumn{3}{|l|}{ (2) Topics of general nutrition } \\
\hline General nutrition for special groups (e.g., vegetarians, vegans, and different cultural groups) & 13 & 56.5 \\
\hline General nutrient information, for example, the role of nutrients, vitamins, and minerals in the body & 12 & 52.2 \\
\hline General food safety & 9 & 39.1 \\
\hline General nutrition, for example, prevention of chronic illnesses such as cancer or heart disease & 6 & 26.1 \\
\hline Other ${ }^{(b)}$ & 3 & 13.0 \\
\hline
\end{tabular}

${ }^{(a)}$ Multiple responses allowed.

(b) Other included "obesity," "eating disorders," and "diets of heart and kidney diseases."

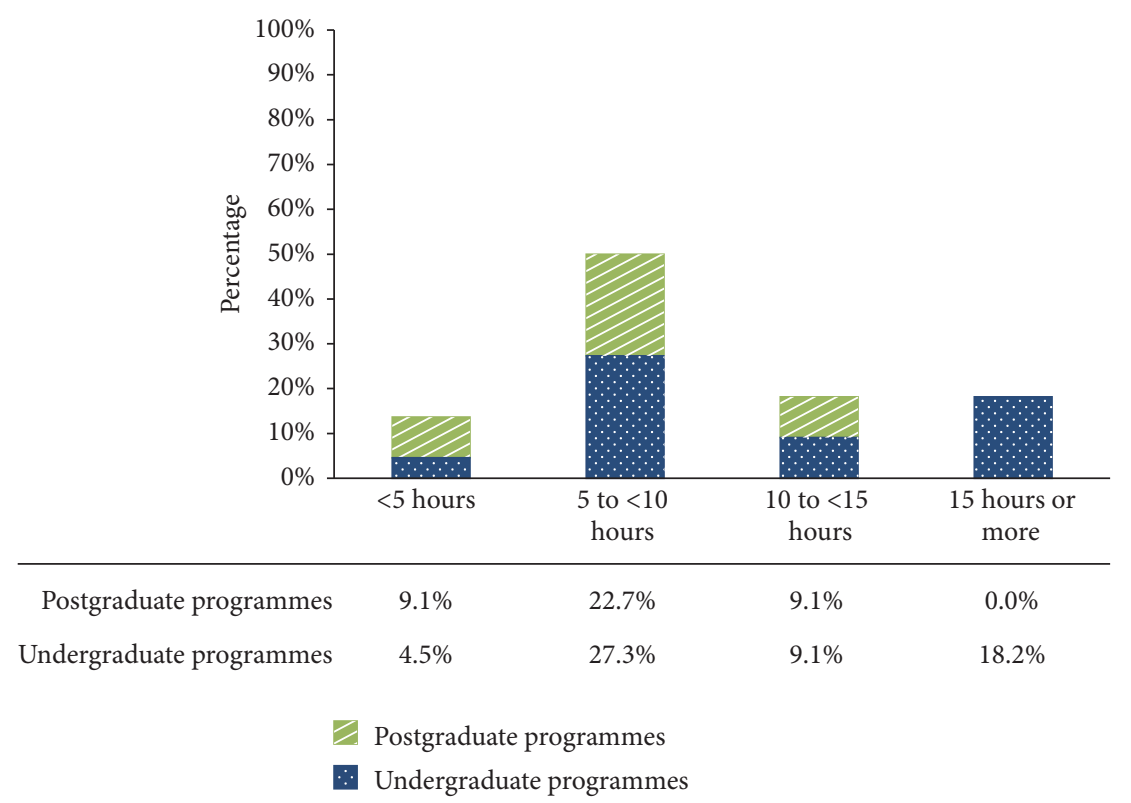

FIGURE 1: Hours allocated to general nutrition and/or nutrition during pregnancy in midwifery curricula by programme type.

during pregnancy were covered but there was less reported coverage of important topics such as "managing weight during pregnancy" (16 of 23) and "nutrition assessment (e.g., reviewing diet for nutrition requirements of pregnancy)" (15 of 23), while topics such as "nutrition and teenage pregnancy" (11 of 23) and "nutrition during pregnancy and different cultural groups" (10 of 23 ) were the least covered topics. It was also noticed that the coverage of topics of nutrition during pregnancy was reported more frequently in comparison to the coverage of topics of general nutrition.
No significant association was found between nutrition topics covered and programme type (undergraduate or postgraduate) or between nutrition topics covered and seeking experts' advice to review programmes' nutrition content.

More than half $(60.9 \%, n=14)$ of the coordinators indicated that nutrition content of their programmes was reviewed and updated on an annual basis, and, within the remaining programmes $(39.1 \%, n=9)$, it was reviewed every 5 years as part of the accreditation cycle. Three coordinators commented that the curricula were reviewed each semester 
or each time a subject was presented. Three other respondents commented that the content was updated continually as new materials and evidence became available. One coordinator stated "not specifically addressed-is embedded across subjects."

Nearly three-quarters $(73.9 \%, n=17)$ of the coordinators reported that the review of nutrition content of their programmes did not involve seeking input from experts (either internal or external). Of those who identified input from experts was sought $(n=6)$, two had consulted a dietitian. A midwifery external advisory committee was reported by another coordinator as the experts involved in reviewing nutrition curricula. The survey did not include a specific item on barriers to consulting experts (including dietitians) for the development, teaching, and/or review of nutrition components of midwifery programmes; however, two respondents indicated that cost was a barrier.

3.2. Stage 2. Seven coordinators participated in the interviews; of these, four coordinated postgraduate midwifery programmes and three coordinated undergraduate programmes. Nutrition content was integrated in all postgraduate programmes and in one undergraduate programme, while the other two undergraduate programmes had designated nutrition units. One of the two programmes having a designated unit also had additional nutrition content integrated into other subjects. The designated unit for the other programme was specified as compulsory by the course coordinator.

Staged presentation of nutrition content was indicated by the coordinators according to life stages related to pregnancy (i.e., preconception, pregnancy, and breast-feeding), according to the level of midwifery care delivered to pregnant women (i.e., normal, complex, and emergency), and/or within topics such as anatomy and physiology. The focus in the content tended to be clinical or problem-oriented (i.e., anaemia, malnutrition, obesity, and diabetes).

One coordinator who had integrated nutrition content pointed out that they did not have a separate topic/lecture for nutrition and it would come up in the discussion of other topics. This may imply that nutrition was not considered formally as part of the curriculum.

We cover a little bit of it when we're talking about anaemia in pregnancy.... Yes.... I think that's about it. And I might say that throughout the year we will discuss, you know, the foods that women will have to avoid when they are pregnant ... especially the ones that causes listeria ... that sort of comes up as a general discussion during lectures.... It is not a separate subject. (Coordinator Four-Postgraduate)

Another coordinator made a few assumptions about how students acquire nutrition knowledge. She assumed that nurses enrolling in midwifery programmes came with previous knowledge and that students would learn about nutrition when learning about antenatal care.
OK. Well, there is no unit specifically about food and nutrition in the midwifery course. Our course is a postgraduate diploma course and all of our students are Registered Nurses, so I guess in one way it's assumed that they come to that course with quite a high degree of general knowledge about health, so that's, I guess, a bit of a background. ... they also learn about the antenatal care of a woman and so quite obviously that entails good health and good diet and it also looks at things like listeria and, you know, foods that they shouldn't eat and the reasons behind that. (Coordinator Two-Postgraduate)

All coordinators considered the nutrition content to be important on some level compared to other topics or units within their programmes. However, this was expressed in different ways. The coordinators who had designated units considered the nutrition units as important as other units. They specified that presenting nutrition as a designated unit was a reflection of the level of this importance.
We ... identified when we were developing our curriculum, the importance of nutrition and the understanding of same for our students ... when working with women during pregnancy. So we actually have a whole unit, a 12 credit point unit, designated to nutrition in the midwifery pro- gramme. Alongside of this ... with our units that cover normal pregnancy, birth, post-natal and high acuity, which is like very complex midwifery experiences, nutrition is dealt with at a unit level as well. (Coordinator Seven-Undergraduate)

Three coordinators considered nutrition to be very important. Two of those coordinators cited the integration of nutrition throughout the curricula as a reason, while one highlighted that teaching about nutrition should be in the context of woman-led care, where the student identifies and discusses nutrition issues specific to that woman instead of getting taught about specific nutrition topics.

I think it's very important, nutrition is very important. But I think it's very important that it's woman-led and student-led rather than us stating students learn this, this and this about nutrition. So we talk about the importance of when they're discussing nutrition and food with a woman that the student finds out what's important to the woman rather than, you know, going through a tick box thing that they've covered everything. (Coordinator Six-Postgraduate)

One coordinator indicated that nutrition was of moderate importance, while another indicated equal importance with other topics but admitted that time allocated to nutrition content did not reflect this status.

...out of the whole 3 years it's talked about in Year 1, one lecture and two tutorials, that's it.... That lets you know how important it is and if 
we don't give it any more time than that the students won't see it as important. (Coordinator Five-Undergraduate)

For programmes with integrated nutrition content, the responsibility was fully that of the midwives (i.e., the coordinators or midwifery academics), with no or little involvement of experts in the field (such as dietitians). Nutritional expertise was not requested, not considered necessary, nor could it be guaranteed.

In programmes with designated nutrition units, one unit was delivered by an academic who was also a dietitian; in the other, the expertise of the dietitian was acknowledged by involving them in teaching the unit. Dietitians as experts were called upon to deliver technical content that midwives were not comfortable or sufficiently skilled to deliver; however, their skills in teaching counselling or how to talk to women about nutrition were not fully used.

...what she [the dietitian] does is gives the...science behind why nutrition is important... the reason I get a dietitian is because they have that in depth knowledge of understanding what happens at the cell level and so on whereas as a midwife, I mean I understand it but I couldn't teach it. I couldn't answer the questions if they were too curly for me, you know, whereas she can. (Coordinator Three-Undergraduate)

One coordinator assumed that diet is "straightforward" in comparison to other issues. She also assumed that a programme would not pass accreditation unless it contained nutrition content.

...in most instances whatever the student is researching, whether it is domestic violence or whether... they're looking at something as straightforward as diet... (Coordinator TwoPostgraduate)

Similarly, the curriculum development and review activities were midwifery driven and relied on the academic responsible for the content to keep up with the literature. In designated nutrition units, one unit had a nutritionist as an assessor. The development and review activities were easier to identify and report. Two coordinators admitted nutrition content did not get reviewed as it was integrated. One of these coordinators reflected that reviewing nutrition content and evaluating how it is taught might be an idea worth considering in the future to assist in preparing students for their role in providing nutrition advice.

No coordinator reported professional or theoretical models as informing their nutrition content, in contrast to the use of such models to support breast-feeding (as was pointed out by two coordinators). Some respondents were not aware of any national midwifery support or guidance in relation to nutrition content.

Well, no [professional or theoretical models to inform nutrition content]. I'll tell you in the module, in our tutorials outline we always put in the ANMC [Australian Nursing and Midwifery Councill Competencies Standards for the Registered Midwife... they're listed so that the student knows that's what they're supposed to be doing... and all that talks about in there, the closest one that would go anywhere ... related to nutrition is competency 5, element 5.1 assess the health and well-being of the woman and baby. So there's nothing really that underlines how we teach about nutrition, it's what we find in the textbooks or our midwifery readings and that's it. (Coordinator Five-Undergraduate)

Coordinators identified specific aspects of the nutrition education within their programmes which would help their students to provide nutrition advice to pregnant women. Some of these aspects included the content itself, how the materials were presented (designated or integrated), the nature of the course (e.g., inquiry based), and the clinical placement including continuity of care.

Most coordinators reported using governmental guidance such as the National Health and Medical Research Council (NHMRC) dietary guidelines and reference values. However, in two instances, this was undertaken by just giving the brochures to the students. One coordinator reported that there was no teaching about dietary guidelines within their programme as students are registered nurses and were assumed to have previous knowledge. Another coordinator assumed that a hospital dietitian would be the source of up to date information for the students.

No. No. I wouldn't say we [follow any national
standards]... as I said, the dietitian at the hospital
actually, we presume, has the most up to date
information and that's what will be discussed
with the women in any case... we will sort of
follow the lead of the dietitian but we ourselves,
I wouldn't say we actually go seeking that kind of
information because we don't actually have a topic
that looks at nutrition into detail. (Coordinator
Four-Postgraduate)

Overall, there was a lack of adoption of approaches that would specifically teach the students how to assess women's nutrition requirements or advise them about achieving such requirements in the programmes included in the study. However, one coordinator indicated that their programme used "motivational interviewing" as a way of working with women who have lifestyle issues (e.g., obesity or smoking). Another one cited a class activity about altering a menu. Three coordinators mentioned that nutrition may be involved in some standard practices as part of caring for women (e.g., practising booking a visit and case studies). Three assumed students would develop those skills during clinical placement, although it was indicated that student exposure to nutrition education during clinical placement could not be guaranteed. There was a concern that any such exposure during placement would be generally problem-oriented and could be based on stereotyping. 
...There's also a part of the course where students look after women in a continuous way called continuity of care... the student would speak to the woman, would educate the woman in a very non-structured way in the form of really focused care about her, so I feel that if the student was looking after a woman that was very well educated and very healthy and that had enough money to buy food and that was in a secure relationship that ... [the student] probably wouldn't spend a lot of time talking to them about good nutrition because they would probably be looking at that woman and saying, this woman understands about good nutrition and it would be approached in a circumspect way. But if on the other hand they were looking after someone who had very little money and who ... didn't have support then ... they would take on that role, they would see that as a much more important part of what they do, if that makes sense. (Coordinator TwoPostgraduate)

All the coordinators thought that the graduates from their programmes would be generally prepared to provide nutrition advice at a basic level to pregnant women. However, one coordinator indicated that a deep understanding of the shortand long-term effects of nutrition on the health of mother and offspring would be lacking.

Some coordinators believed that knowledge of principles such as consultation and referral and woman-centred care would be sufficient preparation for providing nutrition advice at a basic level to pregnant women. Only one programme had formally evaluated their nutrition unit. They obtained positive feedback from their students.

\section{I believe they'd be excellently prepared in that, ... they would be following the principles of woman-led care, they'd be following the principles of consultation and referral, so if there was a woman with specific needs, most of the units have a dietitian that they could refer to and seek advice from ... we are graduating midwives, woman-centred, evidence-based midwives, as far as consultation and referral goes that they would know when further expert advice was needed. (Coordinator Six-Postgraduate)}

The coordinators provided mixed responses when asked about barriers and facilitators within programmes that may hinder or help students to learn to provide nutrition advice. Some participants said that there were no barriers or they were unable to identify specific barriers but then supplied in their description of facilitators an indication of their course inadequacy; or they named specific barriers but then implied that they were "doing enough anyway." Some identified barriers included a lack of a separate nutrition topic (due to lack of time), a lack of face to face interaction, and a lack of a dietitian's involvement. Conversely, their opposites were some of the facilitators. One coordinator mentioned that their programme had no barriers as she believed midwives were not "dietitians," while another one thought that the midwifery academics were professionals who kept themselves up to date with the necessary information.

No [barriers], not really...we could get a dietitian in to talk to the students but their contact time is limited and I think that the level of knowledge that the students need to impart to the pregnant women ... should be well enough covered by the experienced academics that teach them ... those academics ... all of the information that they teach, is informed by research ... it's not storytelling, so they are looking into ... texts that are written and best evidence with published papers in order to prepare the lectures that they give to students and the content that they provide. (Coordinator Two-Postgraduate)

One coordinator indicated that graduating midwives might face barriers such as a poor model of care (i.e., the model fails to allow sufficient time which leads to the provision of problem-oriented nutrition advice). On the other hand, another coordinator acknowledged that factors such as inservice education sessions for midwives with dietitians could help practising midwives provide quality nutrition advice.

Some coordinators commended the current research, with one stating it highlighted the gaps in their curriculum and its clinical focus.

I think this [current research] is a good thing. . .to go through and look at what my colleagues are teaching our students because there are other people who contacted me with similar kinds of studies on other various things in our curriculum and it really highlights when you do this, what is not in our curriculum. And I think curriculums are still basically focused on disease processes. So even though midwives say were all about well and healthy and supporting women that's not what we're spending our 3 years teaching students. (Coordinator Five-Undergraduate)

\section{Discussion}

This study found that Australian midwifery course coordinators considered nutrition education in midwifery curricula and the role midwives can play in this area as important. However, this was not reflected in the nutrition content of the programmes. Nutrition components were included in all programmes represented by survey respondents but hours allocated to nutrition were generally low and topics covered varied. Only two programmes had designated nutrition units. Dietitians were not often involved in teaching nutrition and few programmes involved experts in the review of their nutrition curricula. The interviews revealed that nutrition education tended to be problem-oriented and at times based on various assumptions. Nutrition content was not informed by any professional or theoretical models. The development 
of nutrition assessment skills or practical training for midwifery students in the provision of nutrition advice was lacking.

The variable and few hours allocated to nutrition and small numbers of programmes having designated units are comparable with findings from international research [13, 14]. In the United Kingdom's midwifery programmes, hours allocated to "maternal nutrition" and "obesity/weight management" topics within public health curricula were fewer than 10 hours and these topics were mostly integrated into the curricula [13]. When nutrition is integrated across subjects, it could be perceived as less important and therefore not emphasised as it should be in practice [27]. It would also be more challenging to review coverage of core nutrition topics. In contrast, its importance is highlighted when nutrition is presented as a designated unit, as was identified by some coordinators in this study. From a practical perspective, having nutrition as a stand-alone unit in all midwifery programmes might not be feasible, particularly in postgraduate programmes, where the length of the programme (from 12 to 18 months) might be a challenge. With the challenge of a crowded and ever-expanding curriculum in the education of health care professionals, there is an increased trend for nutrition content to be integrated rather than presented separately [28]. This integration could be considered as a strength if it is done effectively, as it reflects the complexity of practice, where nutrition is rarely discussed in isolation [28]. However, interviews with midwifery coordinators identified that nutrition education integrated across the curricula tended to be problem-oriented and at times inconsistent and based on various assumptions. These assumptions included nursing students' existing nutrition knowledge, students' exposure to nutrition while learning about antenatal care, inclusion of nutrition in accreditations standards, ease of dietary behavioural change, and students' exposure to nutrition during clinical placement. This may be due to the absence of clear national midwifery guidelines on the way nutrition should be included in the curriculum and the absence of specified competencies on what knowledge and skills the students need to acquire [20]. It is at the discretion of each institution.

Generally, nutrition education in health care professionals' education has been identified as inadequate [29], even in those professions such as medicine $[28,30]$, which have received more attention compared to nutrition education within the midwifery discipline. An inability to fit nutrition within crowded curricula is one of the main reasons given for this omission [28]. The failure of professional education to equip graduates to face the evolving challenges in the health care system has also been linked to curricula being "fragmented, outdated, and static" [31] (p. 1923). Several strategies have been identified which might increase integration of nutrition into health care professionals' education, including introducing mandatory policies and legislation, adopting new approaches in the education of health care professionals (e.g., emphasising a competency-based curriculum and utilising information technology in the teaching process), and emphasising a mandatory interprofessional team-based education (including defining the specific roles of each discipline in nutrition education) [29].
The tendency of the nutrition content to be focused on problems or medical issues may be attributed to the medicalisation of pregnancy [32] and high prevalence of obesity and other pregnancy related complications [33], which may have led to the change of midwifery from being a health and wellbeing promoting profession to a one being more focused on risk and disease management. In a survey of more than 300 Australian midwives, around 60\% indicated that they provided nutrition advice only if the pregnant woman had a medical issue and $24 \%$ did that only if the woman asked questions [9]. In the current study, the importance of nutrition being taught in the context of woman-led care was referred to, as was the possibility of the medical or problemoriented focus of nutrition education provided to students during clinical placement and the probability of students stereotyping women when providing nutrition advice (the last two somewhat problematic). According to the philosophy of the Australian College of Midwives (ACM) [34], midwives provide woman-centred care where they work in partnership with women and focus on women's specific health needs, expectations, and aspirations. However, caution needs to be taken not to wait for women to initiate the conversation about diet or base the advice on assumptions related to women's socio-economic status as recent research indicated low levels of nutrition knowledge and adherence to dietary guidelines among pregnant women in spite of the majority having high level of education, motivation, and perceived confidence in adopting a healthy diet [7]. The authors of the study suggested that women's mistaken beliefs in their ability to eat healthily might prevent them from seeking nutrition information from health professionals [7]. Midwifery education needs to highlight the midwife's role in public health, especially in the area of nutrition. This might encourage midwives to become more proactive and offer the opportunity to every woman to receive appropriate nutrition advice, not just when questions are asked or medical issues are present.

Most of the nutrition teaching was done by midwives. With the reported inadequacy of nutrition education for midwives, their carriage of the nutrition topics within the curricula could be quite variable. Dietitians/other nutrition experts were rarely involved in teaching or reviewing the nutrition content as their expertise was not requested or considered necessary or could not be guaranteed. Studies in medical education have reported similar findings [35]. Even when the expertise of a dietitian was involved and acknowledged, their knowledge in the area of behaviour change was not fully used. Practical training on how students can assess pregnant women's nutrition requirements and provide advice to meet these needs was generally lacking. Dietitians/nutritionists are "university-qualified experts in nutrition and dietetics" [36] and their input into the education of other health professionals could be considered highly relevant. Kris-Etherton et al. argued that nutrition education for health professionals needs to be based on a team approach and that dietitians need to be involved not only in the teaching of the content but also in the planning process [29]. Including nutrition experts in the review process of nutrition content might provide some quality oversight and ensure that the curricula were in line with rapidly occurring 
changes that characterise scientific subjects such as nutrition generally and nutrition in pregnancy specifically. The cost and limited availability of dietitians/other nutrition experts were indicated as barriers. Strategies to consider would be collaboration with nutrition educators from the same universities and/or dietitians from community or hospital settings. The development of an online nutrition module by dietitians and other nutrition experts that could be made available to all Australian midwifery programmes is an alternative strategy worth considering. This strategy has been previously implemented in the discipline of medicine [35].

A wide range of nutrition topics was reported to be covered in the surveyed programmes. However, there was less focus on topics involving practical or management skills such as "nutrition assessment (e.g., reviewing diet for nutrition requirements of pregnancy)" and "managing weight during pregnancy" compared to other topics involving more theoretical knowledge. These findings are consistent with the results of previous international research [10, 13]. Equipping midwives with theoretical nutrition knowledge is essential, but so is equipping them with practical or management skills to apply this knowledge, in particular the skills to manage weight gain during pregnancy. This is imperative with the high prevalence of maternal obesity in Australia, negatively impacting the health of pregnant women and their babies [33]. Australian midwives have previously cited lack of adequate education in the areas of gestational weight gain [11] and maternal obesity and how to manage them [12] as a reason for not giving advice [11]. This is supported by the findings of our study which indicated that the topic "managing weight during pregnancy" was covered by a low proportion of the surveyed programmes.

The two topics of nutrition during pregnancy which were least well covered in the programmes were "nutrition during pregnancy and different cultural groups" and "nutrition and teenage pregnancy." These two groups of women are more likely to be at risk of suboptimal nutrition status during pregnancy $[37,38]$. Australia is a multicultural society and it would be anticipated that midwives regularly care for individuals from different cultural and linguistic backgrounds [39]. Australian midwives were found to have low to moderate levels of confidence in advising this group of women about diet [9]. Pregnant teenagers are a vulnerable group and have high nutrition demands [23]. This group also needs to be given specific attention by health professionals, especially as previous research has indicated that they consider the health professionals as their most trusted source of healthy eating information [40]. More coverage of these important topics in midwifery curricula is recommended.

Contrary to their acknowledging nutrition as important, none of the coordinators interviewed identified lack of clear practical approaches to assess women's diet or provide nutrition advice in view of that assessment as barriers. This is in contrast to the ICM [21] core competencies which clearly articulate that midwives' competency in the provision of nutrition advice to pregnant women needs to be based on both knowledge and skills. The National Competency Standards for the Midwife are considered essential in determining what is involved in the midwifery curriculum as it is usually mapped against the standards [17]. Therefore, nutrition or promotion of healthy eating needs to be included in these competency standards. Such standards would make nutrition education consistent across midwifery programmes, so that all midwives would have basic knowledge and skills which might translate into the provision of consistent nutrition advice.

Other policies place expectations on midwifery programmes to review their inclusion of nutrition within their curricula. The Standards of Maternity Care of Australia and New Zealand (revised in 2016) [41] state that information about nutrition and diet should be offered by health professionals to pregnant women at the first contact. Additionally, the recently released clinical antenatal guidelines (models one and two) $[42,43]$, which are intended for all antenatal care providers, outline key nutrition related issues in pregnancy, and the nature of the information that should be provided.

4.1. Limitations and Strengths. Limitations of this study need to be considered when interpreting the findings. The survey was completed by 23 of 41 coordinators and thus the results do not reflect the nutrition content of all Australian midwifery programmes. However, the results reflect $48 \%$ of accredited programmes in 2012 and are therefore likely to reflect common practice and professional expectations of practice. It could be that the study respondents represented coordinators with more nutrition-oriented programmes and the non-respondents coordinators had even lower coverage of nutrition in their programmes. Another limitation is the selfreporting of curriculum content; most of the coordinators acknowledged that their estimation of hours allocated to nutrition was approximate. Identification and quantification of nutrition content can be challenging especially when it is integrated throughout the curriculum. However, estimation is a common method of quantifying hours allocated to nutrition in the literature $[13,14]$. Despite repeated invitations for the interviews, only seven coordinators agreed to participate. The number is small and, therefore, it is unlikely that data saturation was reached. However, participating coordinators were from both undergraduate and postgraduate programmes (with either integrated content or designated nutrition units), providing varied perspectives on nutrition education within these programmes. A strength of this study is that it is the first to explore the nutrition content of midwifery curricula in Australian universities. The mixed-methods approach is another strength, where the interviews provided a deeper insight into midwifery coordinators' perspectives on the nutrition content within their programmes.

4.2. Future Research. In the future, document analysis could be considered by an "authoritative", independent agency so as to maximise access to useful course materials for more accurate evaluation of hours and nutrition content. Prospective studies should explore newly graduated midwives' nutrition knowledge and their preparation for providing nutrition advice to pregnant women. Some of the course coordinators indicated that students would be exposed to more nutrition 
information and practical training in nutrition during clinical placement. Further research would be required to determine the extent of nutrition education acquired by midwifery students during clinical placement. The process of midwifery curricula review and how it affects the integration of nutrition content into the curricula would be a key area of future research. Also needed is examination of effective strategies to integrate nutrition education into midwifery programmes.

4.3. Implications for Midwifery Education. The Australian clinical antenatal guidelines and the Standards of Maternity Care of Australia and New Zealand [41, 43] indicate the need for minimum requirements of nutrition to be included in Australian midwifery education and the inclusion of nutrition knowledge and skills as core competency areas in Australian midwifery competency standards. This may be achieved through consultation and collaboration between nutrition experts, midwifery educators, and professional midwifery bodies such as the ANMAC. Practising midwives and pregnant women need to be also included in such consultations. The findings of this study also have implications for course coordinators of midwifery programmes in other countries, as similar studies have rarely been undertaken.

\section{Conclusion}

Pregnant women need to receive relevant, timely, and accurate information to prevent excess weight gain and to maximise their nutrition-related health and that of their babies. Midwives have a unique role to play in educating pregnant women about their diet and its effects on their health and the health of their children. Graduate midwives need to be prepared, through their education, to fulfil this role. In order to meet new clinical antenatal guidelines and standards of maternity care, midwifery education in Australia needs to reconsider its coverage of nutrition to maximise midwives' ability to provide appropriate nutrition advice to pregnant women.

\section{Competing Interests}

The authors declare that there are no competing interests regarding the publication of this paper.

\section{Acknowledgments}

This research received funding from the Libyan government as part of a doctoral scholarship for (Jamila Arrish). The Libyan government had no role in the study. The authors express their appreciation for all midwifery coordinators who completed the survey and participated in the interviews. The authors also thank Ms. Cheryl Jecht for her assistance in transcribing the interviews, Dr. Alexis St. George for her valuable feedback on the early draft of this paper, and Ms. Elaine Newby for her assistance in the editing process.

\section{References}

[1] P. S. W. Davies, J. Funder, D. J. Palmer, J. Sinn, M. H. Vickers, and C. R. Wall, "Early life nutrition and the opportunity to influence long-term health: an Australasian perspective," Journal of Developmental Origins of Health and Disease, vol. 7, no. 5, pp. 440-448, 2016.

[2] E. R. Hillesund, E. Bere, M. Haugen, and N. C. Øverby, "Development of a New Nordic Diet score and its association with gestational weight gain and fetal growth - a study performed in the Norwegian Mother and Child Cohort Study (MoBa)," Public Health Nutrition, vol. 17, no. 9, pp. 1909-1918, 2014.

[3] E. M. Szwajcer, G. J. Hiddink, L. Maas, M. A. Koelen, and C. M. J. van Woerkum, "Nutrition-related information-seeking behaviours of women trying to conceive and pregnant women: evidence for the life course perspective," Family Practice, vol. 25, supplement 1, pp. i99-i104, 2008.

[4] H. E. Porteous, M. A. Palmer, and S. A. Wilkinson, "Informing maternity service development by surveying new mothers about preferences for nutrition education during their pregnancy in an area of social disadvantage," Women and Birth, vol. 27, no. 3, pp. 196-201, 2014.

[5] R. Hughes, J. Maher, E. Baillie, and D. Shelton, "Nutrition and physical activity guidance for women in the pre- and post-natal period: a continuing education needs assessment in primary health care," Australian Journal of Primary Health, vol. 17, no. 2, pp. 135-141, 2011.

[6] S. J. de Jersey, J. M. Nicholson, L. K. Callaway, and L. A. Daniels, "An observational study of nutrition and physical activity behaviours, knowledge, and advice in pregnancy," $B M C$ Pregnancy and Childbirth, vol. 13, no. 1, article 115, 2013.

[7] K. Bookari, H. Yeatman, and M. Williamson, "Falling short of dietary guidelines-what do Australian pregnant women really know? A cross sectional study," Women and Birth, 2016.

[8] L. M. Garnweidner, K. Sverre Pettersen, and A. Mosdøl, "Experiences with nutrition-related information during antenatal care of pregnant women of different ethnic backgrounds residing in the area of Oslo, Norway," Midwifery, vol. 29, no. 12, pp. E130-E137, 2013.

[9] J. Arrish, H. Yeatman, and M. Williamson, "Australian midwives and provision of nutrition education during pregnancy: a cross sectional survey of nutrition knowledge, attitudes, and confidence," Women and Birth, vol. 29, no. 5, pp. 455-464, 2016.

[10] S. Elias and T. Green, "Nutrition knowledge and attitudes of New Zealand registered midwives," Nutrition and Dietetics, vol. 64, no. 4, pp. 290-294, 2007.

[11] J. C. Willcox, K. J. Campbell, P. van der Pligt, E. Hoban, D. Pidd, and S. Wilkinson, "Excess gestational weight gain: an exploration of midwives' views and practice," BMC Pregnancy and Childbirth, vol. 12, no. 1, article 102, 2012.

[12] S. A. Wilkinson and H. Stapleton, "Overweight and obesity in pregnancy: the evidence-practice gap in staff knowledge, attitudes and practices," Australian and New Zealand Journal of Obstetrics and Gynaecology, vol. 52, no. 6, pp. 588-592, 2012.

[13] J. McNeill, J. Doran, F. Lynn, G. Anderson, and F. Alderdice, "Public health education for midwives and midwifery students: a mixed methods study," BMC Pregnancy and Childbirth, vol. 12, no. 1, article 142, 2012.

[14] R. Touger-Decker, J. M. Benedict Barracato, and J. O'SullivanMaillet, "Nutrition education in health professions programs: a survey of dental, physician assistant, nurse practitioner, and nurse midwifery programs," Journal of the American Dietetic Association, vol. 101, no. 1, pp. 63-69, 2001. 
[15] S. Elias and S. Stewart, "Developing nutrition within the midwifery curriculum," British Journal of Midwifery, vol. 13, no. 7, pp. 456-460, 2005.

[16] K. M. Kolasa, B. Zinn, and N. Moss, "Nutrition education of nurse-midwives: one example," Topics in Clinical Nutrition, vol. 12, no. 3, pp. 58-62, 1997.

[17] ANMAC, Midwife Accreditation Standards 2014, Australian Nursing and Midwifery Accreditation Council, Canberra, Australia, 2014, http://www.anmac.org.au/sites/default/files/ documents/ANMAC_Midwife_Accreditation_Standards_2014 .pdf.

[18] ANMC, Standards and Criteria for the Accreditation of Nursing and Midwifery Courses Leading to Registration, Enrolment, Endorsement and Authorisation in Australia-With Evidence Guide, Australian Nursing and Midwifery Council, Canberra, Australia, 2009, http://www.google.com.au/url?sa= $\mathrm{t} \& \mathrm{rct}=\mathrm{j} \& \mathrm{q}=\& \mathrm{esrc}=\mathrm{s} \&$ source $=$ web \& $\mathrm{cd}=4 \& \mathrm{ved}=0$ ahUKEwjU7ZSMz57QAhWCkpQKHd7yD7wQFggtMAM\&url=http\%3A\% 2F\%2Fwww.ahpra.gov.au\%2Fdocuments\%2Fdefault.aspx\%3 Frecord\%3DWD10\%252F1905\%26dbid\%3DAP\%26chksum\% 3D\%252FJzNzArsTlcD8aivPe3CAA\%253D\%253D\&usg=AFQjCNF90EYWIr2xIk1vc2S2jEKfG_60hA.

[19] ANMC, National Competency Standards for the Midwife, Australian Nursing and Midwifery Council, Canberra, Australia, 2006, http://www.google.com.au/url?sa=t\&rct=j\&q= \&esrc $=s \&$ source $=$ web \&cd $=1 \&$ sqi $=2 \& v e d=0$ hUKEwim8P2rzp7QAhWBipQKHVsSAEsQFggaMAA\&url=http\%3A\%2F\%2F www.nursingmidwiferyboard.gov.au\%2Fdocuments\%2Fdefault .aspx\%3Frecord\%3DWD10\%252F1350\%26dbid\%3DAP\%26 chksum\%3DYp0233q3xmE5YVjiy\%252Fy0mA\%253D\%253D \&usg=AFQjCNHHLIQQPyH72UhRL44JG4-PJW0u_g\&bvm= bv.138169073,d.dGo.

[20] J. Arrish, H. Yeatman, and M. Williamson, "Midwives and nutrition education during pregnancy: a literature review," Women and Birth, vol. 27, no. 1, pp. 2-8, 2014.

[21] ICM, Essential Competencies for Basic Midwifery Practice, International Confederation of Midwives, 2010, http://www.internationalmidwives.org/assets/uploads/documents/CoreDocuments/ICM\%20Essential\%20Competencies\%20for\%20Basic \%20Midwifery\%20Practice\%202010,\%20revised\%202013.pdf.

[22] J. W. Creswell and V. L. P. Clark, Designing and Conducting Mixed Methods Research, Sage Publications Inc, Thousand Oaks, Calif, USA, 2nd edition, 2011.

[23] C. S. Williamson, "Nutrition in pregnancy," Nutrition Bulletin, vol. 31, no. 1, pp. 28-59, 2006.

[24] S. A. Wilkinson and D. Tolcher, "Nutrition and maternal health: what women want and can we provide it?" Nutrition and Dietetics, vol. 67, no. 1, pp. 18-25, 2010.

[25] Better Health Channel, Pregnancy and Diet, State Government of Victoria Department of Health and Human Services, 2014, https://www.betterhealth.vic.gov.au/health/healthyliving/pregnancy-and-diet.

[26] M. A. Neergaard, F. Olesen, R. S. Andersen, and J. Sondergaard, "Qualitative description-the poor cousin of health research?" BMC Medical Research Methodology, vol. 9, no. 1, article 52, pp. $1-5,2009$.

[27] K. M. Adams, M. Kohlmeier, and S. H. Zeisel, "Nutrition education in U.S. medical schools: latest update of a national survey," Academic Medicine, vol. 85, no. 9, pp. 1537-1542, 2010.

[28] K. M. Adams, W. S. Butsch, and M. Kohlmeier, "The state of nutrition education at US medical schools," Journal of Biomedical Education, vol. 2015, Article ID 357627, 7 pages, 2015.
[29] P. M. Kris-Etherton, S. R. Akabas, C. W. Bales et al., “The need to advance nutrition education in the training of health care professionals and recommended research to evaluate implementation and effectiveness," The American Journal of Clinical Nutrition, vol. 99, no. 5, pp. 1153S-1166S, 2014.

[30] K. M. Adams, K. C. Lindell, M. Kohlmeier, and S. H. Zeisel, "Status of nutrition education in medical schools," American Journal of Clinical Nutrition, vol. 83, no. 4, pp. 941S-944S, 2006.

[31] J. Frenk, L. Chen, Z. A. Bhutta et al., "Health professionals for a new century: transforming education to strengthen health systems in an interdependent world," The Lancet, vol. 376, no. 9756, pp. 1923-1958, 2010.

[32] R. Johanson, M. Newburn, and A. Macfarlane, "Has the medicalisation of childbirth gone too far?" British Medical Journal, vol. 324, no. 7342, pp. 892-895, 2002.

[33] H. D. McIntyre, K. S. Gibbons, V. J. Flenady, and L. K. Callaway, "Overweight and obesity in Australian mothers: epidemic or endemic?” Medical Journal of Australia, vol. 196, no. 3, pp. 184188, 2012.

[34] ACM, Philosophy for Midwifery, Australian College of Midwives, Norwood, Australia, 2004, https://www.midwives.org .au/midwifery-philosophy.

[35] K. M. Adams, M. Kohlmeier, M. Powell, and S. H. Zeisel, "Nutrition in medicine: nutrition education for medical students and residents," Nutrition in Clinical Practice, vol. 25, no. 5, pp. 471480, 2010.

[36] DAA, For Health Professionals, Dietitians Association of Australia, Deakin, Australia, 2014, http://daa.asn.au/for-healthprofessionals/.

[37] P. N. Baker, S. J. Wheeler, T. A. Sanders et al., "A prospective study of micronutrient status in adolescent pregnancy," The American Journal of Clinical Nutrition, vol. 89, no. 4, pp. 11141124, 2009.

[38] G. M. A. Higginbottom, H. Vallianatos, J. Forgeron, D. Gibbons, F. Mamede, and R. Barolia, "Food choices and practices during pregnancy of immigrant women with high-risk pregnancies in Canada: a pilot study," BMC Pregnancy and Childbirth, vol. 14, no. 1, article 370, 2014.

[39] M. Williamson and L. Harrison, "Providing culturally appropriate care: a literature review," International Journal of Nursing Studies, vol. 47, no. 6, pp. 761-769, 2010.

[40] N. J. Wise and A. A. Arcamone, "Survey of adolescent views of healthy eating during pregnancy," MCN: The American Journal of Maternal/Child Nursing, vol. 36, no. 6, pp. 381-386, 2011.

[41] The Royal Australian and New Zealand College of Obstetricians and Gynaecologists, Standards of Maternity Care in Australia and New Zealand, The Royal Australian and New Zealand College of Obstetricians and Gynaecologists, Victoria, Australia, 2014, https://www.ranzcog.edu.au/RANZCOG_SITE/ media/DOCMAN-ARCHIVE/Standards\%20in\%20Maternity \%20Care\%20(C-Obs\%2041)\%20Review\%20March\%202016 .pdf.

[42] Australian Health Ministers' Advisory Council, Clinical Practice Guidelines: Antenatal Care-Module 1, Australian Government Department of Health and Aging, Canberra, Australia, 2012, http://www.health.gov.au/antenatal.

[43] Australian Health Ministers' Advisory Council, Clinical Practice Guidelines: Antenatal Care-Module 2, Australian Government Department of Health and Aging, Canberra, Australia, 2014, http://www.health.gov.au/antenatal. 


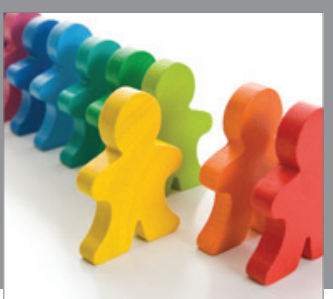

Autism

Research and Treatment
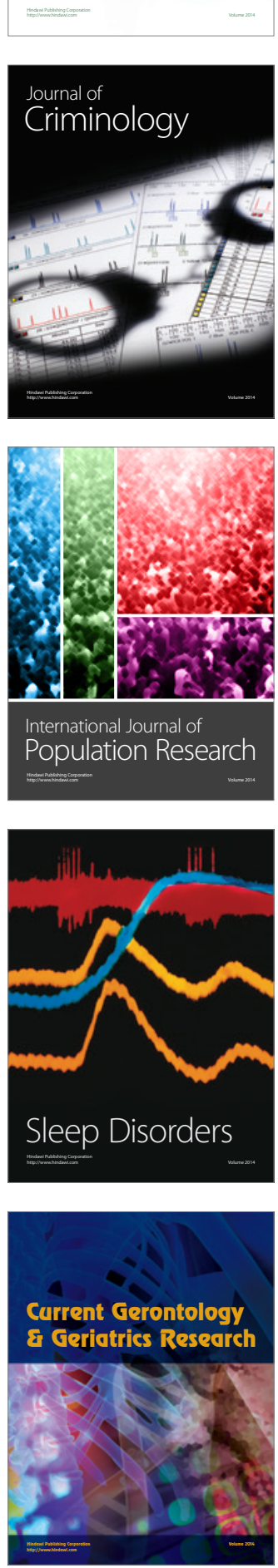

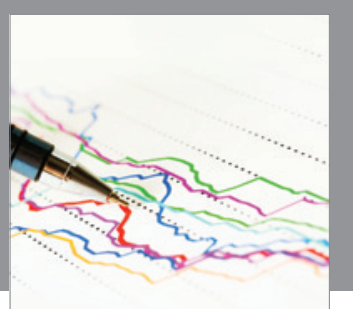

Economics

Research International
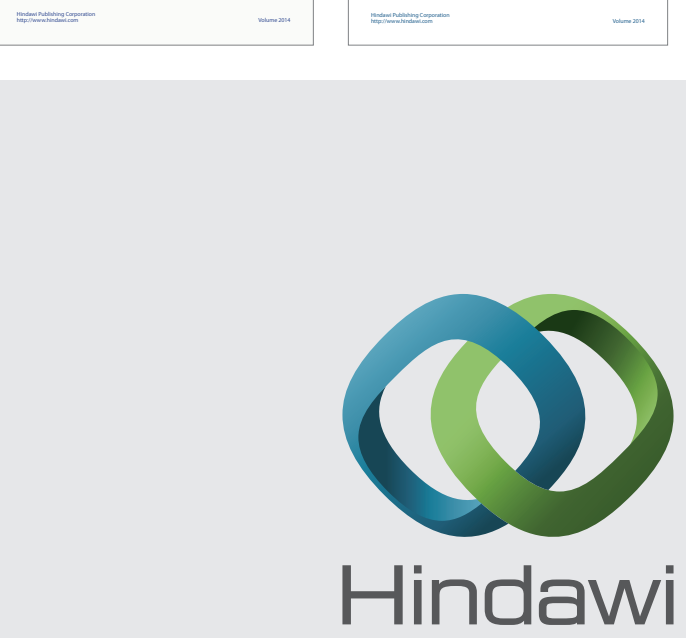

Submit your manuscripts at

http://www.hindawi.com
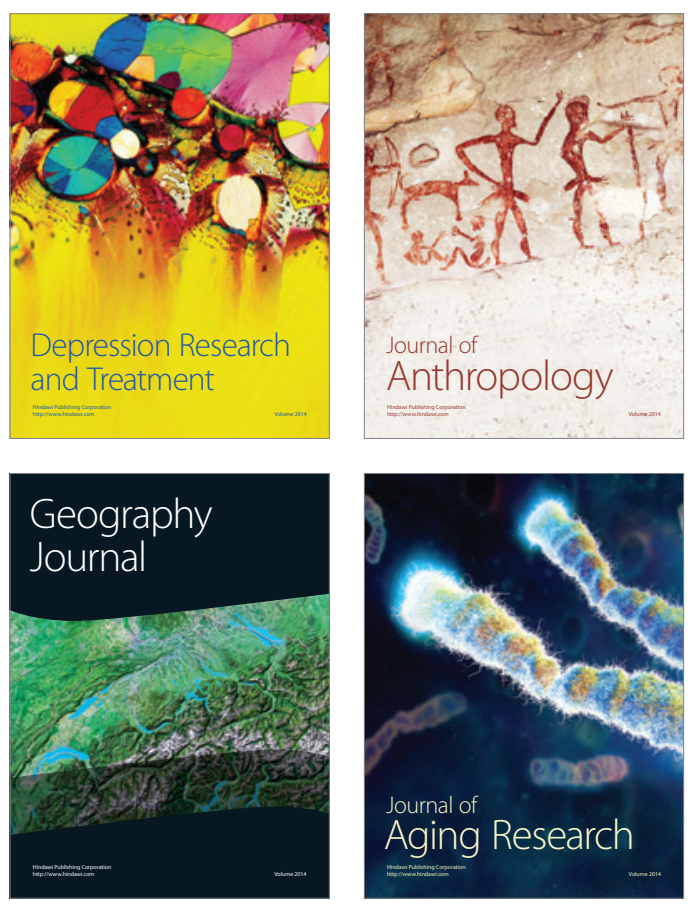
